\title{
INFANTILE SEPSIS AND ITS NUTRITIONAL EFFECTS
}

BY

\author{
A. G. OGILVIE, M.B., B.S., M.R.C.P. \\ Assistant Physician to the Babies' Hospital, and the \\ Royal Victoria Infirmary, Newcastle-upon-Tyne.
}

There is a common variety of infantile infection which is characterized by successive septic manifestations, and by well-marked disturbance of health and nutrition. The clinical observation of 31 cases of this affection forms the basis of the present communication. They have all been personally observed, and for this reason have been selected from the large number seen at the Babies' Hospital. No other method of selection has been employed.

Sepsis of the newly-born has been closely studied, and has formed the subject of many articles ${ }^{10},{ }^{1.5}$, both in the past, and of recent years; and pædiatric text-books deal with it at some length.

Sepsis in later infancy has claimed but a fraction of this interest. When mentioned, it is briefly described as a rapidly fatal illness, and is regarded, indeed, as an acute pyæmia. Feer ${ }^{1}$ thus expresses the prevailing view : ' The outlook generally is bad. In advanced infancy it is not entirely hopeless.'

Such accounts leave a strong impression that they are not based on the observation of cases similar to the majority of those reported here.

It is true that a number of writers (Friedlander ${ }^{3}$, Holsclaw ${ }^{4}$, Druss ${ }^{5}$, Wilson and Schloss ${ }^{6}$, Dean $^{7}$, Floyd $^{8}$, Rogatz ${ }^{9}$, Kugelmass and Lampe ${ }^{13}$ ), and notably Marriott ${ }^{2}$, have given valuable accounts of certain septic processes and their general effects in infants. They have all alluded to the frequency of associated sepsis in the cases described. In all instances, however, their writings have been concerned primarily with a particular lesion, such as otitis or pyelo-nephritis, and no account of general sepsis has emerged. It is possible that extreme familiarity with the condition has led to a lack of interest in the study' of it. Be this as it may, this 'septic disease of infancy' is an extremely important and often puzzling cause of ill-health amongst the infantile population.

It is not suggested that sepsis in later infancy differs in any vital way from sepsis in the newly born. Indeed, sepsis neonatorum is sometimes quite clearly the starting point of infantile sepsis. Again, in the majority of cases, the first septic manifestation is preceded by a period of ill-health commencing in the neonatal stage. 
von Reuss ${ }^{10}$, writing of sepsis neonatorum, says :-

It is quite possible that some disturbance of nutrition or growth at a later period of infancy, apparently due to constitutional weakness, or some marasmic or atrophic state, has its origin in an unknown septic infection of the newborn period, whether it be due to chronic sepsis or to some inferiority and deficient organic resistance resulting from the past infection.

This suggestion is strongly supported by the present series of cases, and when one considers the homes from which most of the cases come, the possibility of an overlooked neonatal infection is readily appreciated. The point will be discussed later.

Generally speaking, sepsis of the newly born is an acute pyæmia, and has been frequently described as such. It is therefore excluded from the present article, though the following qualification is necessary. Not all cases of sepsis neonatorum are acute pyæmias, and this has been recognized by von Reuss, who has given us the best description of this disease. $\Lambda$ final quotation from his book, therefore, will form a good introduction to an account of sepsis in older infants :-

The course of septic infection is extremely multiform. Apart from those violent cases which lead to death within a very short space of time, there are subacute and chronic forms which may last for weeks. Sometimes the disease pursues its course in the most alarming manner, with high fever and all the described general symptoms; in other cases the form of disease is so indefinite that one may finally be in doubt whether a general infection is actually present, or merely general constitutional weakness, the condition resulting from underfeeding, or the onset of nutritional disturbance.

AEtiological factors.-Infancy is here understood to refer to the first two years of life; as far as reaction to infection is concerned, the third year seems to belong rather to early childhood than to infancy.

Of the 31 infants in the present series, 19 were boys and 12 were girls. Prematurity was not an important factor : only three of the children were prematurely born. One child was a full-term twin, and one other was said to be weakly at birth, but with these exceptions it may be taken for granted that the infants were healthy when born. This point has been investigated with some care.

As far as could be ascertained, confinement and puerperium wete uneventful in all cases. A definite history of sepsis in the neonatal period was obtained in four cases only, but it must be emphasized that this apparent freedom from neonatal infection cannot be accepted without question. With two exceptions, the babies came from poor homes, in which exposure to septic infection was likely to be frequent, and its occurrence in any but a severe form likely to be overlooked or forgotten. The majority were members of families of more than four children, living in one, two, or at most three rooms, and poverty and overcrowding cannot be disregarded as important pre-disposing factors.

Only seven of the children had been breast-fed for longer than 10 days. Tuberculosis and syphilis were of no importance as predisposing causes. 
A study of the clinical records suggests a division of the cases into two groups, acute and subacute, according to the mode of onset and the course of the illness, and they are therefore considered in this way. It will be seen that the acute cases are reminiscent of sepsis neonatorum, though the prognosis is much better; whereas the subacute cases have rather a different history.

Acute infantile sepsis.-A healthy, thriving infant suddenly becomes acutely ill; he is, as the Northumbrian mother expresses it, ' dead felled.' If at the same time, or within a few days, an examination of the urine reveals the presence of pus cells in quantity, or should cough, cyanosis and dyspnœa be prominent symptoms, the diagnosis may be easily made. Often, however, more or less severe vomiting, accompanied perhaps by a green, watery diarrhœa, suggests some digestive disturbance which yet seems inadequate to explain the rapid loss of weight and strength which follows; or there is no obvious sign or symptom to indicate the cause of this sudden and even alarming change in the infant's condition. The patient may improve slightly, but remains unhappy, fretful, and underweight. His expression is anxious, he cries hungrily and yet refuses everything that is offered to him except water, of which he takes greedily. $\mathrm{He}$ is pallid and wasted, with more or less diminution of subcutaneous fat, and evidence of dehydration. His muscles are weak and flabby, and a varying degree of anæmia is present, as is shown by a hæmoglobin percentage of 50, 60 or 70. No change is noticed for a week or two, it may be; vomiting and diarrhœa subside or become less pronounced, and little further wasting occurs. Then two to six weeks after the onset, an acute exacerbation of symptoms takes place, with fever, and the appearance of a profuse aural discharge, or perhaps the discovery of pus in the urine, enables a diagnosis to be made. As this disturbance subsides the patient's general condition improves, and he may appear to be convalescent. His weight rises, his appetite returns to normal, and he becomes relatively happy and contented.

This appearance of recovery is, however, frequently illusory. A few weeks later, often before the previous lesion has completely healed, a recurrence of acute symptoms heralds a second septic manifestation : extensive skin sepsis, perhaps, or broncho-pneumonia.

Final recovery may now take place, but further sepsis frequently follows. The infant may suffer from four or five successive septic lesions before his disease comes to an end. Though any of these may prove fatal, the outlook is a favourable one, provided that recovery in the intervals is good, no matter how alarming the exacerbations may be.

Unhappily, by no means all the cases follow this course. In certain others, instead of a degree of recovery in the intervals, there is a steady and often rapid deterioration. The weight falls, the digestive and other symptoms persist or become aggravated, and the child takes less and less interest in his surroundings. The intervals between one septic manifesta- 
tion and another are short, and no attempt at healing is made; the course of the disease is steadily downhill with little or no sign of improvement at any time, and the resemblance to sepsis neonatorum is close.

Six of the twelve cases in this group were of this severe type and all died, the average duration of the illness being eight weeks. Of the remaining six cases, who corresponded to the description given above, only one died. The average duration of these cases was twelve weeks.

Subacute infantile sepsis. - The onset in these cases is insidious, and is in well-marked contrast to the dramatic commencement in the acute group. There is a history of a prolonged period of vague ill-health of from 6 weeks up to 9 months, and followed by the appearance of an obvious septic lesion. In most cases this history dates from the first few weeks of life, but in some the infant thrives for some months, and then gradually ' goes back.' He becomes listless and unhappy, his appetite fails or is capricious and variable, irregular vomiting or diarrhœa perhaps occurs, he ceases to gain weight or slowly wastes, and his muscles become increasingly weak and flabby. His complexion may be noticed to assume a sallow, earthy tinge, and a slowly developing pallor of the mucous membranes and of the palms of the hands suggests a progressive anæmia, which is confirmed by finding a hæmoglobin percentage of 60,50 or 40 .

The appearance of the patient may be suggestive of a chronic infection, but in the first weeks or months of the illness the impression often gained is that of a badly nourished or unsuitably fed baby, or of some nutritional disorder. This impression is often strengthened by the appearance and circumstances of the mother, by her account of the infant's diet, and by the appearance of rickets in other members of the family, if not in the patient himself. She states that no food suits the child, and it is found on enquiry that frequent changes, and irregularity in feeding, have been the rule. The diet, in short, has been ' everything by starts, and nothing long.' If, however, the child is taken into hospital and placed on an adequate and carefully balanced diet, with anti-rachitic treatment should this appear to be advisable, the result is disappointing. The weight may rise a little at first, but the general trend is downward; the appetite does not improve, and recurrent attacks of diarrhœa and vomiting may cause doubt and difficulty in feeding. Anæmia is progressive, and the patient seems to become weaker and flabbier, in spite of all the care that may be taken.

At length, a more pronounced rise of temperature with evidence of general febrile disturbance indicates some fresh development, and in a day or so definite evidence of this is found : and a pustular eruption, or a nasal or aural discharge, perhaps, shows the septic nature of the illness. The lesions of subacute infantile sepsis are slow to heal, but the more acute symptoms of exacerbation subside fairly quickly, and some slight degree of general improvement may take place. Generally speaking, however, the infant's condition remains stationary. As in acute sepsis, successive septic 
manifestations occur, but the degree of recovery is much less in the intervals, and the intervals themselves tend to be longer. An interesting feature is the occurrence of symptoms suggestive of an exacerbation without corresponding change in local signs, or the appearance of any fresh infective focus. There may be fever and toxæmia, an attack of diarrhœa and vomiting, or a mere loss of appetite accompanied by a well-marked fall in weight.

Final improvement commences as insidiously as the disease itself, and continues unchecked by further sepsis. It is not uncommon for skin sepsis or pyuria to occur or recur at this time, but no check in the general improvement is noted, and the lesions heal rapidly. It would appear that a point is reached at which the infant acquires sufficient resistance to enable him to kill his infection.

An improved appetite is usually the first sign of recovery, and this is accompanied by an increased power of digestion. The child's food now seems to do him good, and he gains weight and strength steadily. The anæmia, unaffected by iron medication, now undergoes spontaneous cure, and the patient, who before lay listless in his cot, or sat with his legs crossed, looking tired and bored, shows a new interest in his surroundings and an evident desire to move about. In six or eight weeks he is fit for discharge.

The average duration of the disease in the 19 cases was seven months, although one case ran a course of nearly two years before final recovery took place.

With regard to prognosis, it may be said that the mortality rate in the subacute cases was half that in the acute, and that the more protracted the illness the better the chance of recovery. Six of the nineteen cases died, and their average duration was under five months. The average duration of the 13 cases which recovered, on the other hand, was over nine months.

Recovery, when it has occurred, has been practically complete. All these children have been followed for over two years, and all have remained well, though such a condition as pulmonary fibrosis, which followed pneumonia in a few cases, still gave evidence of its presence, as indeed might be expected.

\section{Discussion.}

The importance of this disease lies in the frequency with which it occurs, the amount of severe illness in babies for which it is responsible, and the serious difficulties of diagnosis and prognosis to which it may give rise.

The influence of sepsis on the general infantile mortality rate is uncertain, as this diagnosis is not accepted by the Registrar-General. It must, however, be not inconsiderable. Again, septic infection is a serious problem from the institutional point of view. The prevention of ward infection is an ever-present consideration in any institution where infants 
are collected together for purposes of treatment, and infantile sepsis as a cause of ward infections stands alone. The nursing of a septic infant requires special precautions, and the indefinite character of the symptoms during certain phases of the disease is an added difficulty. Many cases which would formerly have been regarded as 'feeding' cases are now recognized as cases of infection, and every patient in the Babies' Hospital is regarded as a potential source of infection, and is placed on infectious precautions. Definitely ' clean' cases, such as those of pyloric stenosis, are nursed in special rooms, but the same precautions are observed as an additional protection for them.

The frequency of the disease is shown by the following analysis of the cases admitted to the Babies' Hospital since 1922. In all probability it is under-estimated, as in the earlier years the diagnosis was less likely to be made.

$\begin{array}{llllllr}\text { Sepsis } \ldots & \ldots & \ldots & \ldots & \ldots & \ldots & 180 \\ \text { Digestive and nutritional } & \ldots & \ldots & \ldots & 182 \\ \text { Bronchitis and pneumonia } & \text { (all } & \text { kinds) } & \ldots & 132 \\ \text { Pyloric stenosis } & \ldots & \ldots & \ldots & \ldots & 121 \\ \text { Tuberculosis } & \ldots & \ldots & \ldots & \ldots & 108 \\ \text { Rickets } & \ldots & \ldots & \ldots & \ldots & \ldots & 108 \\ \text { Gastro-enteritis } & \ldots & \ldots & \ldots & \ldots & 71 \\ \text { Congenital defects } & \ldots & \ldots & \ldots & \ldots & 68 \\ \text { Pink disease } & \ldots & \ldots & \ldots & \ldots & \ldots & 45 \\ \text { Prematurity } & \ldots & \ldots & \ldots & \ldots & \ldots & 37 \\ \text { Other conditions } & \ldots & \ldots & \ldots & \ldots & 142\end{array}$

Clinical features.-Clinically the most important feature of the disease is the indefinite nature of the general symptoms, and their variability. They vary from persistent misery and fretfulness, or mere failure to thrive, to recurrent attacks of diarrhoa and vomiting which may be severe and alarming. As an example the following case may be reported :-

Case 1.-Male, aged 6 months. He was healthy when born, though a twin, but had never thrived since the second week, when he had a septic rash. He was always unhappy and continually crying, difficult to feed, and liable to occasional attacks of diarrhœea and vomiting for no apparent reason. He remained persistently underweight, alternately gaining and losing. When first seen he was puny and anæmic, with small, flabby muscles and a perpetual whining cry. His weight at 6 months was only $9 \mathrm{lb} .10 \mathrm{oz}$. General examination revealed little else. The father was an unemployed miner, and malnutrition due to social conditions might appear to be a likely diagnosis. The tuberculin test was negative. On the fourth day after admission, however, pus cells in large numbers were found in the urine. (It may perhaps be observed, in passing, that for the early diagnosis and proper observation of renal sepsis in babies, the microscopical examination of daily specimens of urine is essential : pyuria in them shows wide fluctuations, is intermittent, and is readily overlooked.) The hæmoglobin percentage (Sahli) was 60, the leucocytes numbered 21,000 per c.mm., and a differential percentage count resulted as follows: Polymorphonuclear, 34; lymphocytes, 51; monocytes, 10; meta-myelocytes, 3; eosinophils, 2. Slow improvement took place, and this was steadily maintained throughout the child's stay in hospital. The pyuria cleared in a fortnight, to recur 10 days later, coincident with a very slight check in the general progress. Skin sepsis 
supervened, but both lesions rapidly and finally healed, and he was discharged two months after admission. Cure was evidently complete, and when seen four-and-a-half years later he was well and active, and had remained in good health since discharge.

What view are we to take of this illness? Are we to regard it as a pure nutritional disorder, complicated at the age of 6 months by an infection; or as an infection of long standing, giving rise to marasmic and dyspeptic symptoms?

That nutritional disorder is an important factor in the production of infantile illness is not in dispute, and the circumstances of this child's home were favourable for the production of such disorder, as has been stated.

Closer consideration of the whole history, however, suggests a different view. At the age of 2 weeks this infant had a 'septic rash' over its body. It is, of course, open to us to question the nature of this. But whatever it was, it is clear that before this time the child was healthy and thriving, and that afterwards, up to the time of admission, he was ailing. The rash, even if non-infective itself, may easily have been evidence of the fact of infection. Septic infection is easily overlooked in a workingclass home, but nearly every mother notices when her child is fretful or unhappy, or manifestly compares unfavourably with the children of her neighbours in his rate of progress. Even should she not, her neighbours will themselves eagerly point this out to her. The whole course of the disease in hospital strongly suggests that this period was actually the terminal recovery stage of an infection which had already existed for some time previous to admission. The weight and temperature charts, and the persistence of normal stools throughout, are all opposed to the idea of an acute septic infection occurring in a case of severe nutritional disorder. The steady gain in weight is not what would be expected in the case of a grossly under-nourished child attacked by an acute septic infection : it is surely more suggestive of a highly resistant patient steadily overcoming his disease. It is quite probable that had the baby been born into a home further above the poverty line, he would have recovered more quickly : but this consideration cannot weaken the argument.

This case has been quoted and discussed at length as illustrative of what is considered to be an essential feature of the disease. Further examples, in which the whole or the greater part of the illness has been observed in hospital, could be quoted to support this view, but have been excluded to avoid repetition.

As illustrating the ease with which septic manifestations can be overlooked; the following may be briefly quoted :-

Gase 2.-A female infant, aged 10 weeks, was admitted with a history of violent diarrhœa and vomiting for two days. The symptoms were due to severe renal sepsis, from which the child died 10 days after admission. On examination at the time of entry into hospital, however, a perforation of the right ear drum was noted, and although there was no obvious discharge externally, pus was oozing through the perforation and was present in the middle ear. Careful questioning could not elicit the statement that discharge from the ear had been noticed at any time, and it must be assumed that little 
obvious discharge had ever been present. The fact of infection was, however, indisputable, and the conclusion that the otitis was the primary lesion, and hence the source of the fatal pyelo-nephritis, is difficult to avoid.

Disorders of nutrition are widely discussed at the present time, and have stimulated much valuable original work. Nutritional anæmia, in particular, which has for so long been neglected in this country, is now being placed on a sure footing by Mackay and Parsons. Vitamin and mineral deficiencies, quite rightly, have occupied, and still occupy, much space in medical literature, and the subject of infant feeding has claimed a large amount of medical attention. That such subjects rightly take such an important place is too obvious for argument, but it nevertheless seems quite possible that the rôle of infection, and especially septic infection, may be seriously under-estimated. 'Dyspepsia' and 'marasmus' are unsatisfying terms as final diagnoses, and careful and persistent search for infective lesions, especially septic lesions, should be made before these or similar labels are applied.

Portal of entry of the infection.-It will be gathered from the foregoing remarks, that the exact mode of entry of the infection may be impossible to determine with any certainty. The first known lesion may not be the true primary focus.

The recognition of this difficulty is implied in the varying views which are held as to the most frequent sites of primary septic foci in medical literature. Marriott ${ }^{2}$, for instance, in a series of papers, has strongly expressed the view that aural septic infection is one of the most potent causes of infantile alimentary disorder; and the observation of cases such as those described above certainly gives some support to this view, though hardly encouraging one to go as far as he does in this direction. The extreme importance attached to the ear as the primary focus, also, seems exaggerated. Druss ${ }^{5}$ argues against this view, basing his argument on the chronology of the symptoms and the frequency of post-mortem aural changes in normal subjects. He believes that the bowel is the portal of entry in.such cases. Others support Marriott's view (Holsclaw et al. ${ }^{4}$, Dean $^{7}$, Floyd $^{8}$, Hartman $^{11}$, Preysing $\left.{ }^{12}\right)$.

The matter is indeed impossible of proof at present, because insufficient is known of generalized infantile sepsis. Until careful pathological and bacteriological studies have been made on a sufficient number of cases, the matter can go no further than argument.

A survey of 180 septic cases admitted to the Babies' Hospital indicates that the respiratory route appears to have been greatly under-estimated as a mode of infection in infants, and that the skin and the mouth are frequent sources of septic infection, as they are in sepsis of the newborn. The figures are small, however, and afford no proof.

The source of infection has not been determined in the great majority of cases. In neonatal sepsis this is much easier to trace, and yet cryptogenetic cases are frequent. When first seen months after the primary infection, the problem is usually insoluble, and persistent enquiry has failed to provide an answer in the present series. Septic infection in the 
attendants seems a most probable explanation, but the possible contacts in the homes of the poor are legion.

Maintenance of the infection.-An infection which persists and exerts its influence for so long a time, suggests by analogy with other chronic infective diseases, that it is maintained in some nidus within the body, and acts by producing general toxic effects and local metastases. Such a focus of infection, conveniently referred to as the ' basal lesion,' will vary in activity with the resistance of the tissues of the host and other factors, like any infection. At one time it may produce mild dyspeptic or nutritional disturbance, and at another may become locally virulent; or it may invade the blood stream temporarily, thus giving rise to embolic sepsis.

This basal lesion could be identified in a number of the cases, though in others this was impossible. The latter are thus truly ' cryptogenetic,' and must remain so until more pathological knowledge of the disease is available. It seems likely, however, that in these cases also a basal lesion was present, though not certainly identified.

The fear of arousing a sense of tedium in the reader has led to a severe restriction of the number of cases quoted in any detail, but two illustrations may be given here:-

Case 3.-A boy, agad 5 months, was admitted because of failure to thrive. Born healthy, some vague upset at the end of the second week had been followed by persistent, though irregular, vomiting, with intermittent diarrhœa, and failure to gain weight. On admission some bronchitis was present, but the general impression gained was that of malnutrition and neglect. A week after admission an acute febrile disturbance preceded the obvious occurrence of aural sepsis on the right side. The discharge varied in amount, but final healing did not take place until three months later. During this time repeated crops of pustules and successive skin abscesses continued to appear, and tonsillitis and septic rhinitis als occurred. Final healing of the ear was promptly followed by rapid and permanent disappearance of the skin sepsis, and final recovery.

Case 4.-A male infant was admitted at the age of 7 months with the history that he had thrived well until he had had broncho-pneumonia at the age of 3 months. Since then he had suffered from persistent cough and had failed to gain. He had not been well for 4 months, according to the mother, and indeed, on admission, weighed only $8 \mathrm{lb}$. $13 \mathrm{oz}$. at 7 months. There was marked impairment of percussion note over the left lower lobe and the breath sounds were almost absent over this area. There was a bullous impetigo over the trunk, also, which had been present for a few days. The chest was explored on several occasions with a negative result, although a leucocyte count of over 21,000 indicated an active infection. X-ray examination of the chest showed a marked shadow in the left lower lobe overlapping the heart shadow. The tuberculin reaction was negative. These clinical and radiological signs were slow to clear, and until they did so recurrent skin sepsis was very troublesome. Final disappearance of both signs and X-ray shadow were followed, as in the case just quoted, by rapid and complete healing of the skin infection, and by permanent recovery. Two years later this boy was in good health.

But little comment is required. Both cases point in a suggestive manner to a 'basal' focus as the origin of secondary infection which permanently healed as soon as this cleared up. 
This basal lesion is not necessarily the primary lesion, though often it is so.

\section{Summary.}

Thirty-one cases of septic infection in infants have been studied. Infantile sepsis is an important cause of ill-health and death among babies, and is a potent source of institutional infection.

Like any other disease, the prognosis varies as the resistance of the patient and the size and virulence of the infective dose, but it may be said that subacute cases do much better than acute cases; and that the longer a child survives, the greater its chance of ultimate recovery. The general mortality appears to be about 30 per cent. The portal of entry is perhaps most frequently the respiratory tract, although definite conclusions have not been attempted.

The impression gained is that of some basal septic focus, which produces general toxic symptoms and periodic embolic lesions until such time as the patient acquires sufficient resistance to kill the infection, or until death occurs.

No mention has been made of the pathology and bacteriology of the disease, owing to insufficient data. With regard to the hæmatology, Dr. P. Klenerman is at present studying this aspect at the Babies' Hospital, and her results may be published in the near future.

Finally, emphasis has been laid throughout on the pronounced effect of this affection on the digestive processes and the general nutrition, and on the difficulty in diagnosis to which this may give rise. It has long been recognized that severe digestive and nutritional effects are produced by septic infection in infants, but there has been insufficient recognition in the literature of the insidious character often assumed by the disease, and of the ease with which the cause may be overlooked, in spite of the work of Marriott and his colleagues. Clinically, this is much the most important feature.

\section{REFERENGES.}

1. Feer, E., Textbook of Pediatrics (Trans.), Philad., 1922, 719.

2. Marriott, W. M., Laryngoscope, St. Louis, 1925, XXXV, 592, Am. J. Dis. Child., Chicago, 1925, XXX, 577.

3. Friedlander, A. Acta Pædiat., Stockholm, 1927, VI, 433.

4. Holsclaw, F. M., et al., Am. J. Dis. Child., Chicago, 1930, XXXIX, 746.

5. Druss, J. G., Ibid., 1932, LXIII, 356.

6. Wilson, J. L., \& Schloss, O. M., Ibid., 1929, XXXVIII, 227.

7. Dean, L. W., Arch. Otolaryng., Chicago, 1927, VI, 201.

8. Floyd, M. L., Ibid., 1925, I, 411.

9. Rogatz, J. L., Am. J. Dis. Child., Chicago, 1930, XL, 70.

10. von Reuss, A. R., Diseases of the Newborn, London, 1921, 539.

11. Hartman, Ztschr. f. Ohrenk., 1898, XXXIV, 1.

12. Preysing, Otitis media der Sauglinge, Weisbaden, 1904.

13. Kugelmass, N., \& Lampe, M., Am. J. Dis. Child., Chicago, 1932, XLIII, 291.

14. Byfield, N., Abt's Pediatrics, Philad., 1924, III, 786.

15. Cameron, H. C., Lancet, Lond., 1929, i, 1127. 